Article

\title{
Outcomes and Key Factors of Success for ISO 14001 Certification: Evidence from an Emerging Arab Gulf Country
}

\author{
Marie-France Waxin ${ }^{1}$ (D), Sandra L. Knuteson ${ }^{2, *}$ and Aaron Bartholomew ${ }^{2}$ \\ 1 Department of Management, School of Business Administration, American University of Sharjah (AUS), \\ P.O. Box 26666 Sharjah, UAE; mwaxin@aus.edu \\ 2 Department of Biology, Chemistry and Environmental Sciences, College of Arts and Sciences (AUS), \\ P.O. Box 26666 Sharjah, UAE; abartholomew@aus.edu \\ * Correspondence: sknuteson@aus.edu
}

Received: 20 November 2019; Accepted: 23 December 2019; Published: 28 December 2019

\begin{abstract}
The objectives of this research were: (1) To examine the outcomes and key factors of success (KFS) related to ISO 14001 certification, (2) to compare and contrast these in private organizations (PRIVOs) and public organizations (PUBOs), and (3) in the under-explored context of an Arab Gulf country with an emerging economy: The United Arab Emirates. We used an exploratory, qualitative research approach, based on semi-structured interviews with the environmental managers of 14 UAE organizations from the private and public sector. The five major outcomes of ISO 14001 certification were improved: (1) Environmental performance, (2) organizational reputation and relationships with stakeholders, (3) organizational efficiency, (4) environmental management (EM) practices, and (5) environmental awareness. These outcomes were shared by PRIVOs and PUBOs, although improved resource management, improved relations with stakeholders, and improved EM practices were more common in PUBOs, and improved organizational efficiency was more common in PRIVOs. The six KFS for implementation were: (1) Senior management's support, (2) employees' awareness, involvement and competence, (3) government initiatives and commitment, (4) sufficient organizational resources, (5) adoption of a continuous, integrative, and collaborative approach, and (6) the use of external consultants. These KFS were shared by PRIVOs and PUBOs, although government initiatives and commitment were more common in PUBOs, and sufficient resources were more common in PRIVOs. Our study contributes to a better understanding of environmental management system implementation in emerging countries in general, and in Arab Gulf countries particularly. Our study has implications for business leaders, policy makers, EMS professionals, and educators in the UAE and other emerging countries.
\end{abstract}

Keywords: environmental management systems; outcomes; key factors of success; ownership; private; public; ISO 14001; Arab countries; gulf; UAE

\section{Introduction}

Environmental management systems (EMS) are designed to help organizations "identify, manage, monitor and control their environmental issues in a holistic manner" [1]. The International Organization for Standardization (ISO) 14001 certification system, established in 1996 and updated in 2004 and 2015 [2], has rapidly become the most-utilized EMS worldwide [3]. ISO 14001 certification does not specify particular environmental goals (e.g., reduction of certain pollutants, reduction of energy consumption, etc.) or require that companies meet certain performance standards. Instead, these process standards help organizations better identify and manage their activities that have significant environmental 
impacts and achieve their own environmental goals, which will presumably lead to improved environmental performance (EP) [4].

Based on our literature review on ISO 14001 outcomes and key factors of success (KFS), we have identified four areas in need of further research. First, there is a lack of research on ISO 14001 certification outcomes in emerging countries in general [5], and in Arab countries in particular [6]. The benefits of certified EMSs are less clear in emerging countries, where environmental and social regulations may be lacking or poorly enforced [7] and demand for "green products" may be virtually nonexistent [8]. Second, many studies have examined the benefits or outcomes of EMS certification, both for the organizations and for the environment, the extent to which certification results in positive outcomes remain controversial, however. Many studies have found multiple positive benefits or outcomes following ISO 14001 certification, but other studies have found that the certification process did not lead to any significant changes in organizational performance or practices [2,5]. Third, research on the KFS for EMS certification is more recent and less well-developed than research on EMS certification outcomes. KFS for ISO 14001 certification have rarely been examined thoroughly in the literature [5]. Several studies have been conducted in emerging [9] and Middle-Eastern countries [10-12], but there are no studies from Arab Gulf countries. Fourth, there is a critical lack of research on comparing EMS certification in private and public organizations [6]. Most of the research on EMS certification has been conducted on private-sector organizations, and further research is needed to determine how the outcomes and KFS for EMS certification may differ between private and public organizations [13].

In order to address these four gaps in the literature, our objectives were to: (1) Investigate the outcomes and KFS related to ISO 14001 certification, and (2) compare and contrast these among private and public sector organizations, and (3) in the under-explored context of an Arab Gulf country with an emerging economy. We used an exploratory, qualitative approach, based on semi-structured interviews with environmental managers at 14 private and public organizations in the United Arab Emirates.

The paper is structured as follows: First, we briefly present the context of this study, the UAE, as well as a literature review on the outcomes and KFS for ISO 14001 certification. Second, we describe our research methodology. Third, we present and discuss our findings. We conclude with a discussion of the limitations and theoretical and practical implications of the study.

\section{Literature Review}

\subsection{Our Study Context: The United Arab Emirates, an Emerging Arab Gulf Country}

The United Arab Emirates (UAE) is one of the fastest growing nations in the Gulf, with very high per capita waste generation and greenhouse gas emissions [14,15]. The UAE has become an EM leader in the GCC [6], and has taken steps to become more sustainable, including pledging to reduce overall carbon dioxide emissions by $30 \%$ by 2030 [14]. The UAE Ministry of Climate Change and Environment has developed a National Climate Change Plan of the United Arab Emirates for 2017-2050 [16], which builds on the UAE Green Agenda 2030 [17] and UAE Vision 2021 [18]. These plans work within the 2015 Paris Agreement and UNESCO Sustainable Development Goals [15-17,19] to develop strategies to minimize and adapt to predicted negative climate change impacts. ISO 14001 is the most popular standard in the UAE and the GCC. UAE private and public organizations have readily embraced the ISO 14001 standard and represent $38.4 \%$ of all the organizations certified in the Middle East [20]. However, there is a lack of research on EMS and ISO 14001 in the UAE and the Gulf countries [6]. It is important to understand how UAE organizations perceive the outcomes of successful ISO 14001 certification, and explore the KFS, as these will have an impact on the motivation and commitment of other organizations for allocating resources to their own certification. 


\subsection{Outcomes of ISO 14001 Certification}

Boiral et al. [5] organized EMS certification outcomes into three categories, improved: (1) Environmental management (EM) practices, (2) environmental performance, and (3) environmental awareness and other social aspects. We add a fourth outcome: (4) Improved business performance.

\subsubsection{Improved Environmental Management Practices}

One important outcome of EMS certification is the improved rigor and effectiveness of environmental practices [21,22]. Boiral et al. [5] found that 95\% of organizations improved EM practices with ISO 14001 certification. Some studies found that ISO 14001 certification only led to limited improvements in EM practices and policies, however [23]. A second outcome is improved regulatory compliance. ISO 14001 certification requires that organizations know all of the environmental laws that affect them, and this allows organizations to better anticipate legal risks, reduce the time necessary to become compliant, and reduce fines and penalties [24]. Boiral et al. [5] found that $100 \%$ of ISO 14001 certified organizations improved regulatory compliance. A third outcome of ISO 14001 is improved documentation of EM practices. [24,25]. Only a minority of organizations improve their EM documentation control, however [5]. A fourth outcome is improved supply chain sustainability. Boiral et al. [5] found that ISO 14001 certification led to greener supply chain management in $100 \%$ of the cases examined. ISO 14001 certified companies are more likely to assess their suppliers' environmental performance and require their suppliers to make specific environmental improvements [26].

\subsubsection{Improved Environmental Performance}

Boiral et al. [5] report that $71 \%$ of organizations generally improved EP with ISO 14001 certification $[9,21,27]$, but other studies report mixed results $[24,28]$ or no significant improvement [23, 29-31]. In the literature, there are four outcomes related to EP. The first one is improved employee health and safety. Boiral et al. [5] found that $88 \%$ of organizations reduced environmental risks and safety problems with certification. ISO 14001 certification may reduce environmental accidents at organizations, encourage organizations to reduce pollution and encourage adoption of new practices and technologies, which may in turn improve employee health and safety [32-34]. The second EP outcome is improved waste management. Boiral et al. [5] found that $84 \%$ of organizations had better waste management, including reduced waste production and better recycling due to ISO 14001 certification [21,32,33]. Some studies report mixed results [35] or no improvement [31], however. The third EP outcome is decreased energy and resource consumption. Boiral et al. [5] found that $92 \%$ of organizations had reduced energy consumption [32,33] and resource consumption [21,27,36], with ISO 14001 certification, although other studies have found no reduction [31,34]. The fourth EP outcome is decreased air and water emissions. Boiral et al. [5] found that $63 \%$ of organizations reported reduced air pollution $[33,34,36]$ due to ISO 14001 certification. Other studies have found no significant effect of certification on air pollution, however [29]. Boiral et al. [5] found that 33\% of organizations reduced water pollution due to ISO 14001 certification [33], and for most organizations, certification has no effect $[29,31]$.

\subsubsection{Improved Environmental Awareness, and Other Social Aspects}

There are two main outcomes related to social aspects and environmental awareness. The first outcome is improved image, reputation, and stakeholder relationships. Boiral et al. [5] found that $91 \%$ of organizations benefitted from improved image and stakeholder relations due to ISO 14001 certification, and this was the most commonly reported benefit in their review $[9,21,22,32,37]$. The second outcome is employees' and managers' increased environmental awareness, involvement, and competencies. Several studies have found that EMS certification resulted in increased employees' involvement $[34,38]$ and awareness [9,21,24,32,34], as well as increased managers' involvement [34] and awareness [39]. Other studies reported no substantial changes in employees' awareness and involvement [40] or 
employees' competence [25] following ISO 14001 implementation, however. Boiral et al. [5] found that $83 \%$ of studies reported greater employee training and knowledge, $80 \%$ reported greater managerial involvement, and $69 \%$ reported increased employee involvement.

\subsubsection{Improved Business Performance}

ISO 14001 has the potential to improve business performance in several ways. An improved company image and stakeholder relations may open up new business markets and attract new customers, giving companies a competitive advantage [41]. EMS adoption can also lead to increased profitability by reducing costs through reduced governmental fines, improved energy efficiency, lower resource consumption, and better waste management $[9,33]$. Other studies have found mixed results or no effect on profitability [38,42], however, and ISO 14001 certification can negatively affect a company's share price in some cases [43].

\subsection{Key Factors of Success for EMS Implementation}

Based on the available literature, we have grouped the KFS into five groups.

\subsubsection{Managers' Support and Commitment}

Many studies have found that senior and middle management's support and commitment were the most important KFS for EMS implementation [21,40,44]. Studies conducted in emerging countries found that senior management's commitment facilitated EMS implementation by supporting staff competencies and commitment, creating a change-oriented organizational culture and fostering effective communication $[7,9,10,45]$.

\subsubsection{Employees' Awareness, Training, and Involvement}

Studies conducted in a variety of countries found that employees' awareness and involvement were generally the second most important KFS [7,9,44,45]. Poksinska et al. [37] found that employee training was the most important KFS.

\subsubsection{Internal Motivations for EMS Certification}

Organizations were more likely to benefit from ISO 14001 if they were internally motivated to seek certification. Internally-motivated companies tended to improve both their environmental and financial performances $[42,44,46]$, because they were more likely to integrate EMS practices into their daily activities [23,28]. Companies that become ISO 14001 certified due to external pressure, or only to gain market share, often do not substantially change their actual EM practices, and usually do not improve their EP $[4,23,28,30]$.

\subsubsection{Collaborative Management with Effective Communication}

Collaborative management and good communication between managers and employees helps generate internal commitment towards EMS certification [12,47].

\subsubsection{Other Contextual Factors}

Other contextual factors can influence the successful implementation of ISO 14001 [5]. Larger organizations have greater financial and work force resources to successfully implement EMSs, and smaller firms have higher cost-to-benefit ratios [48]. Organizations that have had an EMS in place for a longer time reported better EP [25]. 


\section{Research Methodology}

Since our topic has not been well-researched in the Gulf, we used an exploratory, qualitative approach $[49,50]$. The study was approved by our University Internal Review Board to ensure compliance with the Declaration of Helsinki.

\subsection{Sample and Data Collection}

We purposefully selected UAE organizations with different types of ownership (private and public), from a variety of industries and of different sizes in order to provide variation in our sample [51], and to allow us to better generalize our results [52]. To be included in the study, participating organizations had to satisfy the following criteria: (1) Be operating for at least seven years in the UAE, (2) include EM among their organizational strategic objectives, (3) be ISO 14001 certified, and (4) have a budget dedicated to EM. In Arab countries, it can be difficult to collect research data [53], so to ensure adequate participation, we used spontaneous calls and emails to target and recruit participating organizations, as well as personal contacts. We initially contacted 10 private and 10 public organizations, and we briefly described the project, received the respondents' agreement to give an interview, collected basic information about the respondent and their organization, and arranged an interview date. A few organizations refused to participate, so our final sample included seven private organizations (PRIVO) and seven public organizations (PUBO). All PRIVOs and PUBOs were for-profit, except for one PUBO that was a government agency. The decision to conduct a limited number of in-depth interviews for this research was made following Eisenhardt [51] and is consistent with similar published studies in the fields of EM, e.g., [6,13] and management [54]. These studies have yielded important insights, despite relatively small sample sizes.

We interviewed the managers in charge of the EMS program in each of these organizations. The interviews were conducted in their offices, in English, and lasted between 60 to $90 \mathrm{~min}$. We chose personal, face-to-face interviews because they allow a greater degree of social interaction between the interviewers and the interviewees [55]. Moreover, in developing countries, research subjects often prefer face-to-face interviews to impersonal questionnaire forms [56], and personal interviews are well accepted in the Arab culture. All respondents declared their informed consent prior to interviews through a signed consent form, and were assured of research material confidentiality. The interview included open-ended questions, and a probing technique was used to gain as much in-depth information as possible. Key interview questions included, "What are the major outcomes of ISO certification in your organization?" and "What are the KFS for the successful design and implementation of the certified EMS in your organization?" Most respondents refused to be recorded, so the interviewers took extensive notes. All participants demanded anonymity for themselves and their organizations, so we report only basic information about the organizations and respondents in Table 1.

\subsection{Data Coding and Analysis}

We analyzed the data at the organizational level. Each interview was transcribed and individually coded by two researchers. Using Layder's [57] approach, the researchers read the interviews several times, and coded relevant segments, based on the interview questions and their knowledge of the existing relevant literature, while remaining open to emerging ideas. Coding results were discussed and considered final when a consensus on each code was reached. King [58] suggested two methods to improve the quality and reliability of the coding process: Quality checks and reflexivity. We ensured quality checking by the fact that two researchers coded the data independently and discussed any disagreement. Reflexivity means that the researchers assess their own perspective and association in the research topic and the way it impacts research outcomes [58]. Different members of the research team iteratively reviewed the codes and the generation of code categories in order to guard against such biases. Codes were regrouped into the different categories of outcomes and KFS. We then applied 
content analysis [59]. We compared the respondents' answers by examining common themes and differences between their respective experiences. Specifically, we conducted cross-case analysis to identify similarities and differences among the private and public organizations with regard to the outcomes and KFS [50].

Table 1. Characteristics of the private and public UAE organizations.

\begin{tabular}{|c|c|c|c|c|}
\hline $\begin{array}{c}\text { Organizations' } \\
\text { Ownership (Private or } \\
\text { Public) and ID }\end{array}$ & $\begin{array}{l}\text { For } \\
\text { Profit? }\end{array}$ & Industry & \# of Employees & $\begin{array}{l}\text { Job Title of } \\
\text { Interviewees }\end{array}$ \\
\hline PUB1 & Yes & Oil and gas & $>5000$ & Sustainability manager \\
\hline PUB2 & Yes & Manufacturing & $1000-5000$ & QHSE manager \\
\hline PUB3 & Yes & Water and electricity & $1000-5000$ & Sustainability manager \\
\hline PUB4 & Yes & Manufacturing & $1000-5000$ & EMS manager \\
\hline PUB5 & Yes & Manufacturing & $1000-5000$ & Sustainability manager \\
\hline PUB6 & Yes & Engineering & $500-1000$ & EM manager \\
\hline PUB7 & No & Public authority & $100-500$ & EM manager \\
\hline PRIV1 & Yes & Water & $100-500$ & HSE manager \\
\hline PRIV2 & Yes & Biotechnology & $1000-5000$ & EMS manager \\
\hline PRIV3 & Yes & Engineering and construction & $>5000$ & EM advisor \\
\hline PRIV4 & Yes & Manufacturing & $>5000$ & EM manager \\
\hline PRIV5 & Yes & Manufacturing & $<100$ & EM manager \\
\hline PRIV6 & Yes & Waste management & $100-500$ & EM manager \\
\hline PRIV7 & Yes & Construction & $<100$ & Sustainability manager \\
\hline
\end{tabular}

\section{Results and Discussion}

We present our findings on the outcomes (Table 2) and KFS (Table 3) of ISO 14001 certification, and compare the results for PRIVOs and PUBOs. We provide direct quotes that support our findings, and discuss our results in the context of the existing literature.

\subsection{Outcomes of ISO 14001 Certification}

The five major outcomes of ISO 14001 certification were improved: (1) Environmental performance, (2) reputation and relationships with stakeholders, (3) organizational efficiency, (4) EM practices, and (5) environmental awareness. These outcomes were shared by both PRIVOs and PUBOs, although improved resource management, improved relations with stakeholders, and improved EM practices were reported more frequently by PUBOs, and improved organizational efficiency was more frequently reported by PRIVOs.

Table 2. Outcomes of ISO 14001 certification among private and public organizations.

\begin{tabular}{|c|c|c|c|c|}
\hline Outcomes & PUBOs (7) & PRIVOs (7) & Total (14) & Similarities and Differences \\
\hline 1. Improved EP & 6 & 7 & 13 & $\begin{array}{l}\text { Similar: General reduction of } \\
\text { environmental impact, } \\
\text { including reduced air, water, } \\
\text { and land pollution, and reduced } \\
\text { carbon footprint }\end{array}$ \\
\hline $\begin{array}{l}\text { Improved waste } \\
\text { management }\end{array}$ & 4 & 5 & 9 & $\begin{array}{l}\text { Similar: Reduced waste } \\
\text { generation and increased } \\
\text { recycling. }\end{array}$ \\
\hline $\begin{array}{l}\text { Improved resource } \\
\text { management }\end{array}$ & 5 & 3 & 8 & $\begin{array}{l}\text { Similar, but more frequent in } \\
\text { PUBOs: Reduced energy and } \\
\text { resource use. }\end{array}$ \\
\hline
\end{tabular}


Table 2. Cont.

\begin{tabular}{|c|c|c|c|c|}
\hline Outcomes & PUBOs (7) & PRIVOs (7) & Total (14) & Similarities and Differences \\
\hline 2. Improved reputation & - & - & - & $x_{1}$ \\
\hline Improved image & 6 & 6 & 12 & $\begin{array}{l}\text { Similar: Improved reputation, } \\
\text { social responsibility image, } \\
\text { brand image. }\end{array}$ \\
\hline $\begin{array}{l}\text { Improved relationships } \\
\text { with stakeholders }\end{array}$ & 5 & 3 & 8 & $\begin{array}{l}\text { Similar, but with some } \\
\text { differences: Both improved } \\
\text { relationships with regulators. } \\
\text { (miao)PUBOs: And with the } \\
\text { community and industrial } \\
\text { partners.(miao)PRIVOs: And } \\
\text { with customers. }\end{array}$ \\
\hline $\begin{array}{l}\text { 3. Improved organizational } \\
\text { efficiency }\end{array}$ & 5 & 7 & 12 & $\begin{array}{l}\text { Similar, but more frequent in } \\
\text { PRIVOs: Improved } \\
\text { organizational efficiency, cost } \\
\text { reduction related to better use of } \\
\text { energy and materials, reduction } \\
\text { of non-compliance costs. }\end{array}$ \\
\hline 4. Improved EM practices & 5 & 2 & 7 & $\begin{array}{l}\text { Similar, but more frequent in } \\
\text { PUBOs: Improved rigor and } \\
\text { effectiveness of EM practices. } \\
\text { Greater regulatory compliance. }\end{array}$ \\
\hline $\begin{array}{l}\text { 5. Improved employee } \\
\text { environmental knowledge, } \\
\text { awareness, involvement }\end{array}$ & 3 & 4 & 7 & $\begin{array}{l}\text { Similar: Improved employees' } \\
\text { knowledge, awareness, } \\
\text { involvement, and commitment } \\
\text { at work. Improved employees' } \\
\text { awareness of environmental } \\
\text { issues outside of work. } \\
\text { Improved community } \\
\text { awareness. }\end{array}$ \\
\hline
\end{tabular}

Source: Interviews with the 14 respondents.

\subsubsection{Improved Environmental Performance}

All of the respondents, except one PUBO, reported a general improvement in EP and reduced environmental impacts. Respondents mentioned reduced air, water, and land pollution, and reduced carbon footprint. One respondent reported reduced environmental risk, and another reported improved worker health and safety.

- "ISO certification led to reduced air emissions ... sea water discharge and reduced greenhouse gases" (PUB5).

The majority of respondents emphasized that certification improved both waste management and resource management in their organizations. Improved waste management included reduced waste generation and increased reuse and recycling of glass, plastic, paper, cartons, metal, and chemical products. Companies also reported examining ways to turn wet waste into compost. Improved resource management was mentioned by PUBOs slightly more than PRIVOs, and included reducing the consumption of energy, water, paper, plastic, and toxic chemicals.

- "ISO certification was at the origin of several projects, such as zero waste to landfill, no landfill on site and recycling projects" (PUB5).

Previous research has shown that most ISO 14001 certified organizations, including those in developing and emerging countries [22], report improved EP. Previous research has also found that 
ISO 14001 certification usually reduces waste production and improves waste management [5,33]. The UAE is one of the world's largest per capita producers of waste [60] and has very high per capita energy and water consumption [61], so reducing waste and using less energy and water are important ways for UAE companies to both limit their impact on the environment and cut costs.

\subsubsection{Improved Reputation}

Improved reputation included improved organizational image and improved relationships with stakeholders. Almost all the organizations reported improved image due to ISO 14001 certification.

- "ISO certification increased our social responsibility image, and helped in creating a good perception, reputation in the market and in the society about our corporate social responsibility" (PUB2).

A majority of companies also reported improved relationships with key stakeholders. Both PRIVOs and PUBOs noted that ISO certification enhanced their relationships with governmental stakeholders, highlighting the importance of maintaining good relations with government institutions and powerful political executives in the UAE. PRIVOs also mentioned that their customers were increasingly conscious of environmental issues, and that ISO certification increased customers' trust and loyalty. PUBOs also noted improved relations with their industrial partners and the local community.

- "ISO certification increased the brand value of the company, increased customer satisfaction, and improved relationships with regulators" (PRIV4).

Previous studies, in a variety of countries, also found that improved organizational image and reputation were the most important and consistent outcomes of ISO 14001 certification $[9,21$, 32]. Certification also frequently improved relationships with stakeholders, including government regulators [33], customers [9], and the overall community [62].

\subsubsection{Improved Organizational Efficiency}

Improved organizational efficiency was reported by most of the PUBOs and all PRIVOs. They reported improved internal operations and organizational efficiency that led to reduced production, logistics, and non-compliance costs. These cost reductions were in addition to reduced costs associated with more efficient use of energy and materials.

- "EMS certification decreased the cost of waste disposal, and helped reducing manufacturing costs" (PUB2).

Other studies have also found that EMSs certification had a beneficial impact on company performance and internal operations $[9,32]$ by reducing harmful emissions, waste production, and resource use, and also by decreasing risks of environmental accidents [9]. Studies from other emerging countries have shown that ISO 14001 certification helped companies avoid non-compliance fines $[33,34]$.

\subsubsection{Improved EM Practices}

Half of the organizations mentioned improved EM practices as an outcome of EMS implementation, and this was more commonly reported by PUBOs. For these companies, EMS certification led to improved rigor and effectiveness of EM practices, and improved regulatory compliance and / or documentation control.

- (ISO certification helped us to) ... "develop and enforce environmental standards across operations" (PUB6).

- (ISO certification helped us in) ... "making sure that there is a sustainability angle in all the activities performed by employees throughout the organization" (PRIV7). 
PUBOs, since they are government-owned, might have more pressure or motivation to improve their compliance with government regulations. Improved EM practices are more frequently mentioned as an outcome of ISO 14001 certification in other studies compared with our study. Boiral et al. [5], for example, found that $100 \%$ of the organizations surveyed reported improved regulatory compliance. Perhaps more organizations in our study had improved compliance, but did not think to mention this in the interviews as an important outcome. Other studies have also found that improved documentation is a less frequently-reported outcome of ISO 14001 certification [5].

\subsubsection{Improved Employees Knowledge, Awareness, Involvement, and Commitment}

Half of the companies reported improved employee EM knowledge, awareness, involvement, and commitment. These outcomes occurred because of the many training and EM initiatives associated with ISO 14001 certification. Some respondents also mentioned increased community awareness of environmental issues due to their companies' outreach activities. The EMS activities at some companies made their employees more aware of environmental issues outside of work, in their communities, as well. This is an encouraging outcome of ISO 14001 certification that is not often reported (but see [39]).

- "ISO certification increased awareness of environmental issues within the company and the community, because our community outreach programs build a good relationship with the community and promote environmentally sound goals" (PUB1).

- "The outreach activities related to the certification program increased the knowledge and awareness of our employees at work, but also at home. For example, they are now more aware of the need for better recycling in all places at home and around the community as well." (PRIV4).

This result is consistent with past studies that found ISO 14001 certification improved employee awareness in most companies [5]. Tan [32] found that employee knowledge of environmental issues generally increased with ISO 14001 certification, but employee commitment was usually unaffected. This is consistent with Boiral et al. [5], who found that a majority of organizations reported increased employee environmental knowledge, but a slightly lower percentage reported actual improvements in employee involvement. Our results suggest that simply educating employees during ISO 14001 certification may not be sufficient, and that organizations should develop initiatives to help employees translate their new environmental knowledge into increased involvement, commitment, and green behavior. Waxin et al. [6] found that UAE employees generally have low environmental awareness, which makes EMS implementation challenging. Our results suggest, however, that training and involvement initiatives linked to ISO 14001 certification have the potential to improve employees' EM knowledge, awareness, involvement, and commitment in the workplace and potentially in the outside community as well.

\subsection{Key Factors of Successful ISO 14001 Implementation}

The six key factors of successful implementation of ISO 14001 (Table 3), in order of importance, were: (1) Management's support and commitment, (2) employees' awareness, involvement, and competence, (3) governmental initiatives and commitment, (4) sufficient organizational resources, (5) adopting a continuous, integrative, and collaborative approach, and (6) using external consultants. These KFS were important for both PRIVOs and PUBOs, although KFS 3 was reported more frequently by PUBOs, and KFS 4 was reported more frequently by PRIVOs. 
Table 3. Key factors of successful implementation (KFS) of ISO 14001 certification among private and public organizations.

\begin{tabular}{|c|c|c|c|c|}
\hline Key Factors of Success & PUBOs (7) & PRIVOs (7) & Total (14) & Similarities and Differences \\
\hline $\begin{array}{l}\text { 1. Senior managers' support } \\
\text { and commitment }\end{array}$ & 5 & 5 & 10 & $\begin{array}{l}\text { Similar: Leadership support } \\
\text { was the most important KFS for } \\
\text { both PRIVOs and PUBOs. }\end{array}$ \\
\hline $\begin{array}{l}\text { 2. Employees' competence, } \\
\text { awareness, and involvement }\end{array}$ & 5 & 5 & 10 & $\begin{array}{l}\text { Similar: Improving employee } \\
\text { knowledge, competence, } \\
\text { awareness, and involvement } \\
\text { were very important KFS. }\end{array}$ \\
\hline $\begin{array}{l}\text { 3. Government initiatives } \\
\text { and commitment }\end{array}$ & 5 & 3 & 8 & $\begin{array}{l}\text { Similar, but more frequent in } \\
\text { PUBOs: Governmental } \\
\text { regulations, incentives, } \\
\text { and commitment were } \\
\text { especially important for PUBOs. }\end{array}$ \\
\hline 4. Organizational resources & 2 & 4 & 6 & $\begin{array}{l}\text { Similar, but more frequent in } \\
\text { PRIVOs: Sufficient budgetary } \\
\text { resources, including for new } \\
\text { equipment and managerial time, } \\
\text { was especially important for } \\
\text { PRIVOs }\end{array}$ \\
\hline $\begin{array}{l}\text { 5. Adopting a continuous, } \\
\text { integrative, } \\
\text { and collaborative approach }\end{array}$ & 3 & 2 & 5 & $\begin{array}{l}\text { Similar: Adopting a consistent, } \\
\text { continuous improvement } \\
\text { management approach, } \\
\text { including using regular audits, } \\
\text { collaboration, and effective } \\
\text { communication between } \\
\text { departments were KFS }\end{array}$ \\
\hline 6. Using external consultants & 2 & 3 & 5 & $\begin{array}{l}\text { Similar: Using external } \\
\text { consultants to supplement a lack } \\
\text { of internal EMS knowledge and } \\
\text { experience was important, } \\
\text { particularly for smaller } \\
\text { organizations. }\end{array}$ \\
\hline
\end{tabular}

Source: Interviews with our 14 respondents.

\subsubsection{Senior managers' Support and Commitment}

Almost all organizations mentioned the importance of senior leadership and management support throughout all the phases of EMS implementation, including formulation of environmental policies, setting environmental objectives, devising key performance indicators, designing, implementing, monitoring, and reviewing the results of the EMS and changing organizational culture. They also mentioned that managers should lead by example, and "walk the talk, by exhibiting green behaviors" to encourage employees to change their behaviors.

- "Top management commitment has been instrumental at both the design and implementation stages" (PUB4).

- "Commitment of management and staff of authority to implement the system ..." (was important) (PUB7).

Our results are similar to previous research, which has found that managers' support and commitment was the most important KSF, in both developed and developing countries $[5,9,10,45]$. Arab cultures are characterized by high power distance, high uncertainty avoidance, and hierarchical organizational cultures, and managers are highly respected $[63,64]$. Leadership support may therefore be especially important for EMS implementation in Arab countries. 


\subsubsection{Employees' Competence, Awareness, and Involvement}

The second KFS, also mentioned by almost all of the respondents, is employees' awareness, knowledge, competence, and involvement in EMS. Some organizations initiated training to improve the EM knowledge and competence of the employees directly responsible for the EMS only. Others organized training and involvement initiatives for all employees to raise company-wide EM awareness and engagement, improve attitudes toward EM initiatives, and change the organizational culture. Respondents mentioned various employee involvement initiatives including: Company newsletters, initiating or improving recycling, soliciting employee suggestions, forming problem-solving teams, and going on "green" trips, like beach cleanups.

- "Qualified, experienced and skilled people in the plant were a KFS, and also employees' attitude towards EMS, such as pride and satisfaction in the company" (PUB5).

- "The establishment of a network of qualified staff was a KFS for EMS implementation" (PUB6).

This result is also consistent with previous studies that have generally found that the second most important KFS for EMS implementation was improving employees' awareness, involvement, and competencies [45]. Greater employee involvement in EM improved EP [65], and involving all employees in ISO 14001 certification is better, not just the managers and specialists directly involved with the EMS [66]. Factors that encourage employees' green behaviors include: Improving their EM knowledge, encouraging pro-environment attitudes, and making it easier for them to engage in green behaviors, such as easier recycling [67]. Waxin et al. [6] found that employees' lack of knowledge, skills, and experience was the most important challenge to EMS implementation in the UAE, so education and training activities are crucial in this region.

\subsubsection{Government Initiatives and Commitment}

A majority of PUBOs and a minority of PRIVOs reported that governmental regulations, incentives, and commitment to EMS adoption were KFS. The UAE government has encouraged EMS adoption in recent years [68]. Several respondents mentioned that they need to closely follow governmental initiatives, with more PUBOs mentioning that they receive commitment and support for EMS implementation from governmental agencies. Several PUBOs also mentioned that federal government and Dubai municipality actions and representatives really inspired them to actively implement environmental management plans.

- “Commitment from the government's leaders, the positive role of ... (government programs) ... , all these initiatives encourage and guide us to excel" (PUB3).

- "The requirement of Benchmarking and compliance with Dubai Municipality inspired us to excel" (PRIV2).

Previous studies have found that internal motivation was an important KFS, but in our study the third most frequently reported KFS was governmental initiatives and commitment. Organizational leaders and managers in the UAE pay close attention to governmental advice on organizational practices. Governmental laws are a main driver of ISO 14001 implementation in the UAE [6]. In the last decade, the UAE national government has established many environmental initiatives and regulations, and non-compliance with regulations can lead to substantial fines and even jail sentences [69]. The Dubai government, for example, plays a critical, authoritarian role in providing a strong developmental vision and an efficient government apparatus to encourage the Emirate's economic and social development [70].

\subsubsection{Financial and Non-Financial Organizational Resources}

A KFS for half of the PRIVOs and a minority of the PUBOs was sufficient financial and non-financial organizational resources. This included having sufficient budgets for employee 
training, managerial time, and purchasing new equipment. Several respondents mentioned that "new environmentally-friendly equipment can be quite expensive, so it is important to have sufficient financial resources" to decrease the organization's negative environmental impact.

With the UAE's recent push for greater environmental sustainability [19], the PUBOs may receive ample governmental financial support, meaning insufficient resources may not pose a problem for them, and they would not identify this as a KFS. Other research has identified insufficient organizational resources as one of the most important barriers to successful EMS implementation, both globally $[7,9,12,33]$ and locally [6].

\subsubsection{Adoption of a Continuous, Integrative, and Collaborative Management Approach}

A minority of organizations reported adoption of a continuous, integrative, and collaborative management approach to EMS implementation as a KFS. Several respondents mentioned the need to integrate EMS activities into daily operations, which necessitated collaboration and teamwork between managers of different departments, and clear and efficient communication between managers and employees. Several respondents also mentioned the importance of regular, rigorous audits to achieve EMS outcomes.

- "Collaboration between project-based environmental officers, coordinators and third party consultants is an important factor of success. Tools enforced with precision and rigor as a requirement of ISO 14001 are also part of it." (PRIV4).

- "We keep sustainability practices up to date. There is a need of continuous improvement and innovation of ecofriendly procedures, and we share ideas and information with companies and communities outside our sector to ensure competitiveness and efficiency" (PUB1).

Our results are similar to the findings of previous studies. Effective communication and coordination between departments is an important KFS to achieve EMS goals [12]. Consistently monitoring and tracking all of an organization's environmental activities and performance-related information are also KFS for improving environmental performance with ISO 14001 [9].

\subsubsection{External Consultants}

External consultants that helped organizations' internal EMS team were a KFS for a minority of organizations. Respondents stressed the importance of working closely with consultants to avoid delays in implementation. Small companies noted the importance of consultants more frequently, and these consultants provided the EMS knowledge and experience that these companies lacked internally. Several respondents also complained about the high cost of consultants.

- "Having experts with the right industry experience, not just designing the plan but implementing it as well" ... (is important) (PRIV7)

The use of consultants has been identified as a KFS before, particularly for smaller organizations [9, 10]. Boiral et al. [5] noted that the role of consultants in the ISO 14001 certification and auditing processes is usually ignored, and requires further examination. Waxin et al. [6] noted a lack of locally developed expertise in EMS as a challenge to ISO 14001 implementation, and this could necessitate hiring external consultants.

Although none of our respondents formally mentioned "green human resource management' (green HRM) as a KFS, we note that several KFS, such as management and leadership support, employees' knowledge, awareness, attitudes and competencies, and employee training programs implemented during ISO 14001 certification all relate to green HRM. Research has established that green HRM practices lead to improved environmental and organizational performance [66,71]. Unfortunately, strategic HRM practices have yet to be fully implemented in the UAE, and strategic HRM is a nascent field in the UAE and Gulf region [64], which might explain why our respondents did not specifically mention green HRM. 


\section{Conclusions}

\subsection{Limitations}

Our study is an exploratory attempt to provide further insights into the outcomes and KFS related to ISO 14001 in UAE organizations. Our study has several limitations, which do not significantly affect our main findings, but point the way to further research. We used a small sample of ISO 14001 certified organizations, with well-established EMS programs in a single Gulf country. Most of the public organizations in our sample are state-owned, but are managed like private businesses. We did not account for the organizations' size, business sector, or the amount of time that they had been certified. Similar to most EMS studies, we surveyed managers that were directly involved in the promotion and implementation of the EMS within their organization, so our results could be significantly influenced by social desirability bias [72]. Despite these limitations, our study provided interesting insights that could serve as a basis for further research. Having a small sample size, and using organizations from only a single emirate, prevents us from claiming that our sample is representative of UAE organizations in general. We did find a high level of agreement between the 14 respondents, however, and we may have reached theoretical saturation despite low sample size. Further research could use quantitative approaches to study the outcomes, KFS, and other elements of EMS in the UAE and other Gulf countries. Further research could also investigate the effect of green HRM on EMS certification and $\mathrm{EP}$ in this region.

\subsection{Theoretical Contributions}

The major outcomes of ISO 14001 certification reported by the UAE organizations we surveyed were improved: (1) Environmental performance, (2) organizational reputation, (3) organizational efficiency, (4) EM practices, and (5) employees' EM knowledge and awareness. These outcomes were mostly similar in PRIVOs and PUBOs, with PUBOs reporting improved resource management, stakeholder relations and EM practices more frequently, and PRIVOs reporting improved organizational efficiency more frequently. Our findings generally support the results of previous studies on EMSs.

The major KFS related ISO 14001 implementation were: (1) Senior managers' support and commitment, (2) employees' knowledge, awareness, involvement, and competence, (3) government initiatives and commitment, (4) sufficient organizational resources, (5) adoption of a continuous, integrative, and collaborative approach, and (6) the use of external consultants. These KFS were shared by PRIVOs and PUBOs, although government initiatives and commitment were more common in PUBOs, and sufficient resources was more common in PRIVOs. The alignment of EM/ EMS strategies with government policies and initiatives, such as UAE Vision 2021 and the National Climate Change Plan for 2017-2050 [17,19], encourages the organizations, especially the PUBOS, to develop a long-term commitment to EM. Senior managers' support and commitment, as well as employees' knowledge, awareness, and involvement, are the two most important KFS we identified, which is consistent with previous literature. The importance of collaborative management and organizational resources as KFS is also consistent with other studies. Our study highlights that limited resources may be less of a problem for well-supported government companies. Finally, our results show that in the UAE, governmental support and commitment is an important KFS, particularly for PUBOs.

Overall, we found that the outcomes and KFS were mostly similar between private and public organizations, and were similar to those that have been reported across the world in previous literature. Our study contributes to a better understanding of EMS research in emerging countries in general, and Arab Gulf countries in particular.

\subsection{Practical Implications}

First, our research presents several implications for business leaders, public policy makers, EMS professionals, and educators in the UAE. Since the GCC countries have similar cultural, social, and economic characteristics [64], our findings in the UAE could also be relevant for organizations in the 
other GCC countries. Understanding the outcomes and KFS of EMS certification in the Gulf emerging markets could enable organizations to devise more effective business strategies or government policies, and employ evidence-based practices in order to promote more effective EMS certification.

Second, our research has implications for EMS education and training for employees and managers. The successful implementation of EMS programs requires the support of highly involved and knowledgeable managers, equipped with effective change management, teamwork, and communication skills. Business schools in the GCC can play a role in the development of future pro-environmental leaders. In the USA and Canada, but also in developing countries like the Philippines and China, MBA programs have started to include EM courses to train managers in initiating and managing EM projects [73]. Although the UAE has predicted a continuing increase in Green Jobs in the country and region in the coming decades [19], very few environmental or sustainability management related degrees are available in the GCC region at the BSc, MSc, or PhD levels [74]. Academic institutions should include EM components in their curricula, and organizations implementing ISO 14001 should plan their training programs carefully.

Author Contributions: All researchers contributed significantly at various phases throughout the process. Conceptualization, S.L.K. and M.-F.W.; Methodology, S.L.K. and M.-F.W.; Software, M.-F.W.; Validation, M.-F.W.; Formal Analysis, M.-F.W. and A.B.; Investigation, S.L.K.; Resources, S.L.K.; Data Curation, M.-F.W.; Writing-Original Draft Preparation, M.-F.W.; Writing-Review \& Editing, M.-F.W., S.L.K., and A.B.; Visualization, S.L.K. and M.-F.W.; Supervision, S.L.K.; Project Administration, S.L.K. All authors have read and agreed to the published version of the manuscript.

Funding: This research received no external funding.

Acknowledgments: The researchers would like to express their appreciation to all the participating organizations, environmental professionals, and the research assistants that helped with this project. This research did not receive any specific grant from funding agencies in the public, commercial, or not-for-profit sectors.

Conflicts of Interest: The authors declare no conflict of interest.

\section{References}

1. ISO. ISO 14000 Family-Environmental Management; International Organization for Standardization (ISO): Geneva, Switzerland, 2019.

2. Dos Santos, C.M.G.; de Oliveira e Aguiar, A. ISO 14001 and international trade. Indep. J. Manag. Prod. 2019, 10, 22-40. [CrossRef]

3. Mas-Machuca, M.; Viadiu, F.M. Still implementing ISO 14000 for the same reasons? Int. J. Qual. Res. 2019, 13, 115-130. [CrossRef]

4. Curkovic, S.; Sroufe, R. Using ISO 14001 to promote a sustainable supply chain strategy. Bus. Strategy Environ. 2011, 20, 71-93. [CrossRef]

5. Boiral, O.; Guillaumie, L.; Heras-Saizarbitoria, I.; Tayo Tene, C.V. Adoption and Outcomes of ISO 14001: A Systematic Review. Int. J. Manag. Rev. 2018, 20, 411-432. [CrossRef]

6. Waxin, M.-F.; Knuteson, S.L.; Bartholomew, A. Drivers and challenges for implementing ISO 14001 environmental management systems in an emerging Gulf Arab country. Environ. Manag. 2019, 63, 433-436. [CrossRef] [PubMed]

7. Massoud, M.A.; Fayad, R.; Kamleh, R.; El-Fadel, M. Environmental management system (ISO 14001) certification in developing countries: Challenges and implementation strategies. Environ. Sci. Technol. 2010, 44, 1884-1887. [CrossRef] [PubMed]

8. Blackman, A. Alternative Pollution Control Policies in Developing Countries. Rev. Environ. Econ. Policy 2010, 4, 234-253. [CrossRef]

9. Sambasivan, M.; Fei, N.Y. Evaluation of critical success factors of implementation of ISO 14001 using analytic hierarchy process AHP: A case study from Malaysia. J. Clean. Prod. 2008, 16, 1424-1433. [CrossRef]

10. Hessami, H.Z.; Golsefid-Alavi, M.; Shekaf, S.M.; Mavi, R.K. Evaluation of Success Factors of ISO 14001-Based EMS Implementation and Ranking the Cement Industry Using the TOPSIS Method. J. Appl. Environ. Biol. Sci. 2012, 2, 523-530. 
11. Hariz, S.; Bahmed, L. Assessment of environmental management system performance in the Algerian companies certified ISO 14001. Manag. Environ. Qual. Int. J. 2013, 24, 228-243. [CrossRef]

12. Arab, A.; Ghasemian Sahebi, I.; Modarresi, M.; Ajalli, M. A Grey DEMATEL Approach for Ranking the KSFs of Environmental Management System Implementation (ISO 14001). Calitatea 2017, 18, 115.

13. Walker, H.; Di Sisto, L.; McBain, D. Drivers and barriers to environmental supply chain management practices: Lessons from the public and private sectors. J. Purch. Supply Manag. 2008, 14, 69-85. [CrossRef]

14. Charfeddine, L.; Khediri, K.B. Financial development and environmental quality in UAE: Cointegration with structural breaks. Renew. Sustain. Energy Rev. 2016, 55, 1322-1335. [CrossRef]

15. FCSA. UAE Numbers Report: Key Statistics and Data for Global Competitiveness and Sustainable Development in the UAE; Federal Competitiveness and Statistics Authority (FCSA): Dubai, UAE, 2018.

16. MoCCE. National Climate Change Plan of the United Arab Emirates for 2017-2050; UAE Ministry of Climate Change and Environment (MoCCE): Dubai, UAE, 2017.

17. MoCCE, G. UAE Green Key Performance Indicators; Green Development Department, UAE Ministry of Climate Change \& Environment (GDD MoCCE): Dubai, UAE, 2019.

18. Vision 2021. Vision 2021 Report: United in Ambition and Determination; UAE Government, Prime Minister's Office, Ministry of Cabinet Affairs and the Future: Abu Dhabi, UAE, 2010.

19. MoCCE. UAE Green Jobs Program: Jobs \& Skills for the UAE's Green Economy Transformation; UAE Ministry of Climate Change and Environment (MoCCE): Dubai, UAE, 2019.

20. ISO. The ISO Survey 2017 of Management System Standard Certifications (1999-2017); International Organization for Standardization (ISO): Geneva, Switzerland, 2018.

21. Zeng, S.; Tam, C.; Tam, V.W.; Deng, Z.M. Towards implementation of ISO 14001 environmental management systems in selected industries in China. J. Clean. Prod. 2005, 13, 645-656. [CrossRef]

22. Turk, A.M. ISO 14000 environmental management system in construction: An examination of its application in Turkey. Total Qual. Manag. 2009, 20, 713-733. [CrossRef]

23. Boiral, O. Corporate Greening Through ISO 14001: A Rational Myth? Organ. Sci. 2007, 18, 127-146. [CrossRef]

24. Morrow, D.; Rondinelli, D. Adopting corporate environmental management systems: Motivations and results of ISO 14001 and EMAS certification. Eur. Manag. J. 2002, 20, 159-171. [CrossRef]

25. Lopez-Fernandez, M.C.; Serrano-Bedia, A.M. Organizational consequences of implementing an ISO 14001 environmental management system an empirical analysis. Organ. Environ. 2007, 20, 440-459. [CrossRef]

26. Arimura, T.H.; Darnall, N.; Katayama, H. Is ISO 14001 a gateway to more advanced voluntary action? The case of green supply chain management. J. Environ. Econ. Manag. 2011, 61, 170-182. [CrossRef]

27. Darnall, N.; Kim, Y. Which Types of Environmental Management Systems Are Related to Greater Environmental Improvements? Public Adm. Rev. 2012, 72, 351-365. [CrossRef]

28. Prajogo, D.; Tang, A.K.; Lai, K.-H. Do firms get what they want from ISO 14001 adoption? An Australian perspective. J. Clean. Prod. 2012, 33, 117-126. [CrossRef]

29. Gomez, A.; Rodriguez, M.A. The effect of ISO 14001 certification on toxic emissions: An analysis of industrial facilities in the north of Spain. J. Clean. Prod. 2011, 19, 1091-1095. [CrossRef]

30. Boiral, O.; Henri, J.-F. Modelling the impact of ISO 14001 on environmental performance: A comparative approach. J. Environ. Manag. 2012, 99, 84-97. [CrossRef] [PubMed]

31. Zobel, T. ISO 14001 certification in manufacturing firms: A tool for those in need or an indication of greenness? J. Clean. Prod. 2013, 43, 37-44. [CrossRef]

32. Tan, L.P. Implementing ISO14001: Is it beneficial for firms in newly industrialized Malaysia? J. Clean. Prod. 2005, 13, 397-404. [CrossRef]

33. Alemagi, D.; Oben, P.M.; Ertel, J. Implementing environmental management systems in industries along the Atlantic coast of Cameroon: Drivers, benefits and barriers. Corp. Soc. Responsib. Environ. Manag. 2006, 13, 221-232. [CrossRef]

34. Nguyen, Q.A.; Hens, L. Environmental performance of the cement industry in Vietnam: The influence of ISO 14001 certification. J. Clean. Prod. 2015, 96, 362-378. [CrossRef]

35. Ghisellini, A.; Thurston, D.L. Decision traps in ISO 14001 implementation process: Case study results from Illinois certified companies. J. Clean. Prod. 2005, 13, 763-777. [CrossRef] 
36. Martin-Pena, M.L.; Diaz-Garrido, E.; Sanchez-Lopez, J.M. Analysis of benefits and difficulties associated with firms' Environmental Management Systems: The case of the Spanish automotive industry. J. Clean. Prod. 2014, 70, 220-230. [CrossRef]

37. Poksinska, B.; Dahlgaard, J.J.; Eklund, J.A. Implementing ISO 14000 in Sweden: Motives, benefits and comparisons with ISO 9000. Int. J. Qual. Reliab. Manag. 2003, 20, 585-606. [CrossRef]

38. Link, S.; Naveh, E. Standardization and discretion: Does the environmental standard ISO 14001 lead to performance benefits? IEEE Trans. Eng. Manag. 2006, 53, 508-519. [CrossRef]

39. Rondinelli, D.; Vastag, G. Panacea, common sense, or just a label? The value of ISO 14001 environmental management systems. Eur. Manag. J. 2000, 18, 499-510. [CrossRef]

40. Balzarova, M.A.; Castka, P.; Bamber, C.J.; Sharp, J.M. How organisational culture impacts on the implementation of ISO 14001:1996-A UK multiple-case view. J. Manuf. Technol. Manag. 2006, 17, 89-103. [CrossRef]

41. Dangelico, R.M.; Pontrandolfo, P. Being 'Green and Competitive': The Impact of Environmental Actions and Collaborations on Firm Performance. Bus. Strategy Environ. 2015, 24, 413-430. [CrossRef]

42. Ferrón-Vílchez, V. Does symbolism benefit environmental and business performance in the adoption of ISO 14001? J. Environ. Manag. 2016, 183, 882-894. [CrossRef]

43. Cañón-de-Francia, J.; Garcés-Ayerbe, C. ISO 14001 Environmental Certification: A Sign Valued by the Market? Environ. Resour. Econ. 2009, 44, 245-262. [CrossRef]

44. Boiral, O. Managing with ISO Systems: Lessons from Practice. Long Range Plan. 2011, 44, 197-220. [CrossRef]

45. Kaur, H. Impact of human resource factors on perceived environmental performance: An empirical analysis of a sample of ISO 14001 EMS companies in Malaysia. J. Sustain. Dev. 2011, 4, 188-211. [CrossRef]

46. Heras-Saizarbitoria, I.; Landín, G.A.; Molina-Azorín, J.F. Do drivers matter for the benefits of ISO 14001? Int. J. Oper. Prod. Manag. 2011, 31, 192-216. [CrossRef]

47. Zhu, Q.; Sarkis, J.; Cordeiro, J.J.; Lai, K.H. Firm-level correlates of emergent green supply chain management practices in the Chinese context. Omega 2008, 36, 577-591. [CrossRef]

48. Campos, L.M.S. Environmental management systems (EMS) for small companies: A study in Southern Brazil. J. Clean. Prod. 2012, 32, 141-148. [CrossRef]

49. Myers, M.D. Qualitative Research in Business and Management, 2nd ed.; Sage Publication: London, UK, 2013.

50. Miles, M.B.; Huberman, A.M. Qualitative Data Analysis: An Expanded Source Book, 2nd ed.; Sage Publishers: Newbury Park, CA, USA, 1994.

51. Eisenhardt, K.M. Building Theories from Case Study Research. Acad. Manag. Rev. 1989, 14, 532-550. [CrossRef]

52. Yin, R.K. Case Study Research: Design and Methods, 5th ed.; Sage Publication: Thousands Oaks, CA, USA, 2014.

53. Zahra, S.A. Doing Research in the (New) Middle East: Sailing with the Wind. Acad. Manag. Perspect. 2011, 25, 6-21. [CrossRef]

54. Waxin, M.F.; Lindsay, V.; Belkhodja, O.; Zhao, F. Workforce localization in the UAE: Recruitment and selection challenges and practices in private and public organizations. J. Dev. Areas 2018, 52, 99-113. [CrossRef]

55. Easterby-Smith, M.; Thorpe, R.Y.; Lowe, A. Management Research-An Introduction; Sage Publications: London, UK, 1991.

56. Ahlstrom, D.; Young, M.N.; Chan, E.S.; Bruton, G.D. Facing constraints to growth? Overseas Chinese entrepreneurs and traditional business practices in East Asia. Asia Pac. J. Manag. 2004, 21, 263-285. [CrossRef]

57. Layder, D. Sociological Practice: Linking Theory and Social Research; Sage Publications: London, UK, 1998.

58. King, N. Template Analysis [Online]; School of Human \& Health Sciences, University of Huddersfield: Huddersfield, UK, 2007.

59. Mostyn, B. The content analysis of qualitative research data: A dynamic approach. In The Research Interview, users and approaches; Brenner, M., Brown, J., Cauter, D., Eds.; Academic Press: London, UK, 1985; pp. 115-145.

60. Kaza, S.; Yao, L.; Bhada-Tata, P.; Van Woerden, F. What a Waste 2.0: A Global Snapshot of Solid Waste Management to 2050. In Urban Development Series; World Bank: Washington, DC, USA, 2018.

61. UAE MEI. United Arab Emirates' Fourth National Communication Report; UAE Ministry of Energy and Industry (UAE MEI): Abu Dhabi, UAE, 2018.

62. Raines, S.S. Implementing ISO 14001-An international survey assessing the benefits of certification. Corp. Environ. Strategy 2002, 9, 418-426. 
63. Klein, A.; Waxin, M.-F.; Radnell, E. The impact of the Arab national culture on the perception of Ideal Organizational Culture in the United Arab Emirates: An empirical study of 17 firms. Educ. Bus. Soc. Middle East. Issues 2009, 2, 44-56. [CrossRef]

64. Waxin, M.-F.; Bateman, R. Chapter 7, Human Resource Management In The United Arab Emirates. In Handbook of Human Resource Management in the Middle East; Mellahi, K.P.B., Ed.; Edward Elgar Publishing Limited: Cheltenham, UK, 2016.

65. Del Brío, J.Á.; Fernández, E.; Junquera, B. Management and employee involvement in achieving an environmental action-based competitive advantage: An empirical study. Int. J. Hum. Resour. Manag. 2007, 18, 491-522. [CrossRef]

66. Renwick, D.; Redman, T.; Maguire, S. Green human resource management: A review and research agenda. Int. J. Manag. Rev. 2013, 15, 1-14. [CrossRef]

67. Ones, D.; Dilchert, S. Measuring, Understanding, and Influencing Employee Green Behaviors. In Green Organizations: Driving Change with I.O. Psychology; Huffman, A.H., Klein, S.R., Eds.; Routledge: New York, NY, USA, 2013; pp. 115-148.

68. UAEGP. Environment and Energy: Environment Budget, Policy and Laws; Official Government Portal (UAEGP): Abu Dhabi, UAE, 2019.

69. Singh, K. Legislation: Environmental Law Regime in the United Arab Emirates: An Investor's Guide to Environment Compliance in the Construction Industry. Electron. J. Islamic Middle East. Law 2014, 2, 83-91.

70. Hvidt, M.C. The Dubai Model: An Outline of Key Development-Process Elements in Dubai. Int. J. Middle East Stud. 2009, 41, 397-418. [CrossRef]

71. Obeidat, S.M.; Al Bakri, A.A.; Elbanna, S. Leveraging “Green” Human Resource Practices to Enable Environmental and Organizational Performance: Evidence from the Qatari Oil and Gas Industry. J. Bus. Ethics 2018, 1-18. [CrossRef]

72. Arnold, H.J.; Feldman, D.C. Social Desirability Response Bias in Self-Report Choice Situations. Acad. Manag. J. 1981, 24, 377-385. [CrossRef]

73. ACBE. Beyond Grey Pinstripes 2011-2012: Top 100 MBA Programs: Preparing MBAs for Social and Environmental Stewardship; Aspen Centre for Business Education (ACBE): Aspen, CO, USA, 2011.

74. UAE CAA. CAA Accredited Programs Portal; UAE Commission on Academic Accreditation (UAE CAA): Abu Dhabi, UAE, 2019.

(C) 2019 by the authors. Licensee MDPI, Basel, Switzerland. This article is an open access article distributed under the terms and conditions of the Creative Commons Attribution (CC BY) license (http://creativecommons.org/licenses/by/4.0/). 